\title{
Effective Interventions to Promote the Mental Health of Caregivers of Patients with Breast Cancer - A Systematic Review
}

\author{
Seyedeh Zeynab Hossein Nezhad ${ }^{1}$, Forouzan Elyasi² ${ }^{2}$ Noraddin Mousavinasab ${ }^{3}$, Elahe Samami ${ }^{4}$, Zohreh Shahhosseini ${ }^{5}$
}

${ }^{1,4}$ Department of Midwifery, Mazandaran University of Medical Sciences, Sari, Iran. ${ }^{2}$ Department of

Psychiatry, Psychiatry and Behavioral Sciences Research Center, Sexual and Reproductive Health Research

Center, Addiction Institute, School of Medicine, Mazandaran University of Medical Sciences, Sari, Iran.

${ }^{3}$ Department of Biostatics, Health Sciences Research Center, Addiction Institute, School of Health, Mazandaran University of Medical Sciences, Sari, Iran. ${ }^{5}$ Department of Midwifery, Sexual and Reproductive Health Research Center, Mazandaran University of Medical Sciences, Sari, Iran.

\section{ABSTRACT}

Breast cancer is one of the most important health problems in Iran and the world, which accounts for about one third of all gynaecological cancers and is the second most common cancer after lung cancer and the most common cause of cancer mortality among women. Considering the extent of the impact of breast cancer in all physical, psychological, and social dimensions on the patient and her caregivers, the purpose of this study is to review the effective interventions in promoting the mental health of breast cancer caregivers.

A systematic review study with a comprehensive search of Internet sites, Google Scholar, Cochrane Library, Elsevier, Springer, Science Direct, Web of Science, PubMed, Scopus and Iranian databases such as Scientific Information Database (SID) and Magiran was conducted using the keywords intervention, promotion, mental health, caregivers, and breast cancer. A total of 28,188 related articles without year limit and 8 articles were obtained manually. Then, out of these articles, 27,964 articles were excluded due to duplication, 119 articles due to non - relevance, 94 articles were in the screening stage of abstracts and 13 articles in the full text review stage, and finally, the quality of 6 experimental and semi - experimental clinical trial studies was evaluated using Jadad scale.

Interventions in effective studies in promoting mental health of caregivers of patients with breast cancer include education, support package, psychosocial intervention, and motivational interview. The results of studies showed that all interventions improved the quality of life, reduced the burden of care and positive changes in the psychological dimension of caregivers. Also, four studies based on Jadad scale were of good quality.

According to the results of the present study, which is based on the effect of all interventions on positive changes in the psychological dimension of caregivers' lives, and due to the fact that the number of studies in this field was limited and out of 6 studies, 4 studies were of good quality, it seems more and better studies are needed in order to access stronger evidence to implement effective interventions in promoting the mental health of caregivers of breast cancer patients.

\section{KEY WORDS}

Interventions, Promotion, Mental Health, Caregivers, Breast Cancer
Corresponding Author: Dr. Zohreh Shahhosseini, Department of Sexual and Reproductive Health Research Center, Mazandaran University of Medical Sciences, Sari, Iran. E-mail: zohrehshahhosseini@gmail.com

DOI: $10.14260 / \mathrm{jemds} / 2021 / 354$

How to Cite This Article: HosseinNezhad SZ, Elyasi F, Mousavinasab $N$, et al. Effective interventions to promote the mental health of caregivers of patients with breast cancer - a systematic review. Evolution Med Dent Sci 2021;10(22):17151722, DOI: $10.14260 /$ jemds/2021/354

Submission 24-01-2021, Peer Review 07-04-2021, Acceptance 13-04-2021,

Published 31-05-2021.

Copyright (C) 2021 Seyedeh Zeynab Hossein Nezhad et al. This is an open access article distributed under Creative Commons Attribution License [Attribution 4.0 International (CC BY 4.0)] 


\section{BACKGROUND}

Cancer is one of the most critical health issues world wide. ${ }^{1}$ Breast cancer accounts for about one - third of all female cancers, the second most common cancer after lung cancer and the leading cause of cancer death.2,3 Cancer is currently the third leading cause of death after cardiovascular disease and accidents. ${ }^{4-6}$ All types and stages of cancer not only affect the patients themselves but also their relatives could be seriously affected, among which the followings can be mentioned: physical needs, 7,8 emotional strains,, 910 uncertainty for the future, ${ }^{11}$ alteration of roles and lifestyle due to the unique role of women in the family, 12 fear of death and loneliness, ${ }^{13}$ sexual anxiety in spouses ${ }^{14}$ and financial problems. ${ }^{15}$ It has been pointed out that there is a burden of care and stress on patients' caregivers. ${ }^{16}$ The distress identifies the care burden that a caregiver feels due to caring for the patient, ${ }^{17}$ which, in addition to stress caused by taking care of a patient, she tends to lose her adaptability, making her feel depressed, frustrated, anxious, and desperate. ${ }^{18-20}$ In this regard, studies show that with the predisposition to the disease, the incidence of psychological problems, ${ }^{21}$ quality of sexual life, ${ }^{22}$ and job performance ${ }^{23,24}$ of breast cancer caregivers experience undesirable changes. In the long run, these adverse effects cause physical health problems by negatively affecting the immune system and increasing the incidence of cardiovascular diseases. ${ }^{25,26}$ Despair and uncertainty about the future and fear of loneliness are sometimes reported as significant problems commonly found in the caregivers of patients with breast cancer. ${ }^{27}$ According to what has been mentioned above, today, special attention is paid to caregivers' supportive needs of patients with breast cancer. While training and psychological interventions, the importance of stress management and increasing caregivers' quality of life should be emphasized.28 Otherwise, consequences would be inadequate patient care, abandonment of the patient, family isolation, despair of social support, and disruption of family relationships. ${ }^{9,11,13,29,30}$ To reduce the burden of care, stress, and anxiety management in caregivers of cancer patients, various methods have been implemented, including psychosocial interventions, ${ }^{31,32}$ providing training packages to increase awareness of the disease, its complications, and familiarity with treatment process, ${ }^{33}$ providing support packages according to the needs of caregivers, 34,35 providing support programs based on COPE and psychological training. ${ }^{36,37}$ These studies have been performed on all types of cancer. However, the results were different.

For example, in a study by Gabril et al. examining the impact of psychosocial intervention on caregivers of cancer patients, it was revealed that psychosocial intervention would reduce the burden of care and stress on caregivers, and this reduction was found to be sustainable after multiple follow ups. However, the Northouse et al. concluded that such interventions are not sustainable Since caregivers of patients with breast cancer, similar to patients, will experience adverse effects during treatment, they are referred to as latent patients. It is worth noting that the results of studies on interventions performed for patient caregivers are contradictory.

Therefore, one of the methods that can resolve these contradictions and ambiguities between the initial studies is to write the study in a structured or systematic review. ${ }^{38}$ In this study, we intend to put together a set of studies, the results from studies allowing the reader to examine various works on a subject simultaneously.

Since no study has been conducted on the effect of interventions on promoting the mental health of caregivers of patients with breast cancer, the current study was performed as a systematic review.

\section{METHODS}

\section{Research Questions}

Have interventions been effective in promoting the mental health of caregivers of patients with breast cancer?

Extract keywords

Researchers used the following keywords in both Persian and English in their search strategy:

["Stress" or "Distress"] and ["Breast Cancer" or "Breast Neoplasm" or "Mastectomy" or "Breast Tumour" or "Breast Carcinoma" or "Mammary Cancer" or "Breast Malignant" or "Malignancy"] and ["Chemotherapy" or "Pharmacotherapy" or "Drug Therapy" or "Neo - Adjuvant Chemotherapy" or "Adjuvant Chemotherapy OR" Medicine Treatment "] and [" Intervention "or" Program "and" Non - Pharmacological Intervention "and" Psychological Intervention "and" Supportive Intervention "and" Supportive group "and" Cognitive Behavioural Therapy "and" Cognitive Therapy "and" Mindfulness "and" Mindfulness - based Stress Reduction "and" Counseling "and" Group Counseling "and" Education "and" Psychotherapy "and" Behaviour Therapy "and" Psychoeducation "and" Emotional Schema Therapy "and" Telephone Intervention "and" Social Intervention "and" Religion Therapy "and" Spiritual Therapy "and" Hope Therapy "and" Complementary and Alternative medicine "and Acupuncture "and" Acupressure "or" Massage Therapy "or" Yoga "or" Hypnosis "or" Exercise "or" Music Therapy "OR" Reiki Therapy "and" ART Therapy "]

\section{Search in the Existing Databases}

Search in the Google Scholar, PubMed, Scopus, Springer, Elsevier, Cochrane Library, Science Direct, Web of Science, Magiran and Scientific Information Databases was done to identify all published electronic articles, without time limit. The list of identified articles was also manually searched in journals to extract articles on related topics. The last search was conducted on December 4, 2020.

\section{Extraction of Articles Based on Selection Criteria}

All relevant studies were extracted during a systematic search. After removing duplicates, irrelevant articles were identified by title, abstract, and full text. The selection process of the final articles was done independently by two researchers. Also, in case of any disagreement, the third researcher made the final decision (Figure 1).

\section{Inclusion and Exclusion Criteria}

All the following eligible studies were considered for the present systematic study - Clinical and quasi - experimental trial studies focused on the effect of psychological and nonpsychological interventions aimed at promoting mental health in caregivers of patients with breast cancer, studies in which 
the sample size and the intervention results were fully expressed. Furthermore, studies without desirable characteristics and abstracts presented at conferences not available in the full text were excluded from the study.

Checking the quality of articles based on checklists after searching in different databases, the data was extracted, and the quality of the entered studies was examined using the Jadad score. ${ }^{39}$ This checklist was taken from a systematic review study.

The Jadad scale consists of two direct and indirect parts related to bias control (Bias) and includes 3 main terms: random allocation, double-blind and sample loss related to pilot studies' bias control.5,39,40 These 3 direct expressions are the general Jadad scale and are used in all areas of medical science. Numerous studies have used only three direct expressions, and some others use both direct and indirect expressions. ${ }^{39,41,42}$ In this study, 3 direct expressions were used.

The scoring system in three direct expressions is such that the first expression is related to the randomization of samples, where randomization is mentioned, score 1 and where the randomization steps are mentioned, score 2 is assigned to the study (score range $2-0$ ). The second term refers to the twoway blinding of the study. Score 1 belongs to mentioning the word double-blind in the study, and score 2 belongs to mentioning the blinding process (range of scores 2 - 0 ).

In the third phrase, which is related to mentioning the number and causes of sample loss, if the number of sample loss and its cause has been mentioned, a score of 1 point is obtained. Otherwise, it is scored zero (range of scores 1 - 0). According to the sum of three direct expressions, the maximum overall score of this scale is 5 points, which is calculated at the end of the score of the item. Jadad score of fewer than three points indicates low quality, and a score of three points or more indicates high quality. ${ }^{39,40,43}$ (Table 1).

\begin{tabular}{|c|c|c|c|c|c|c|}
\hline \multicolumn{7}{|c|}{ Jadad Scale Items (Directly) } \\
\hline $\begin{array}{l}\text { Sl. } \\
\text { No. }\end{array}$ & $\begin{array}{c}\text { Authors / } \\
\text { Year }\end{array}$ & $\begin{array}{l}\text { Was the Study } \\
\text { Described as } \\
\text { Randomized? }\end{array}$ & $\begin{array}{l}\text { Was the } \\
\text { Study } \\
\text { Described as } \\
\text { Double - } \\
\text { Blinded? }\end{array}$ & $\begin{array}{l}\text { Was There a } \\
\text { Description of } \\
\text { Withdrawals } \\
\text { and Dropouts? }\end{array}$ & $\begin{array}{l}\text { Total } \\
\text { Score }\end{array}$ & $\begin{array}{c}\text { Quality } \\
\text { Study }\end{array}$ \\
\hline 1 & $\begin{array}{l}\text { Terry et al. } \\
2019\end{array}$ & 1 & 0 & 1 & 2 & Poor \\
\hline 2 & $\begin{array}{l}\text { Gabriel et al. } \\
2018\end{array}$ & 2 & 0 & 1 & 3 & Good \\
\hline 3 & $\begin{array}{l}\text { Kucheknejad } \\
\text { et al. } 2016\end{array}$ & 2 & 0 & 1 & 3 & Good \\
\hline 4 & $\begin{array}{l}\text { Bahrami et } \\
\text { al. } 2013\end{array}$ & 2 & 0 & 1 & 3 & Good \\
\hline 5 & $\begin{array}{l}\text { Northouse } \\
\text { America } \\
2005\end{array}$ & 2 & 0 & 1 & 3 & Good \\
\hline 6 & $\begin{array}{c}\text { Carla et al. } \\
2017\end{array}$ & 0 & 0 & 1 & 1 & Poor \\
\hline
\end{tabular}

\section{Data Extraction and Final Report}

After reading the abstract and the full text of the qualified articles, the desired data was extracted for writing the present study. Each study's required data that included the author / year, place, purpose, age, sample size, tools, type-duration, and follow-up of the intervention and results. Finally, the data extracted from the articles was classified and reported as the full - text systematic review (Table 2).

\begin{tabular}{|c|c|c|c|c|c|c|c|c|}
\hline $\begin{array}{l}\text { Sl. } \\
\text { No. }\end{array}$ & $\begin{array}{l}\text { Author / } \\
\text { Year }\end{array}$ & Place & Goal & Age & $\begin{array}{l}\text { Sample } \\
\text { Volume }\end{array}$ & Tools & $\begin{array}{c}\text { Intervention Type \& } \\
\text { Intervention Duration } \\
\text { Intervention Follow-up }\end{array}$ & $\begin{array}{l}\text { Results } \\
\text { S: Significant } \\
\text { NS: Non- } \\
\text { Significant }\end{array}$ \\
\hline 1 & $\begin{array}{l}\text { Terry et al. } \\
2019\end{array}$ & $\begin{array}{l}\text { Southwest } \\
\text { America }\end{array}$ & $\begin{array}{l}\text { The effect of supportive } \\
\text { care in the management of } \\
\text { psychological distress in } \\
\text { patients and their } \\
\text { caregivers }\end{array}$ & $40-55$ & $\begin{array}{l}230 \\
\text { TIPCG: } 116 \\
\text { SHEG: } 114\end{array}$ & $\begin{array}{l}\text { PROMIS } \\
\text { GSDS }\end{array}$ & $\begin{array}{l}1 \text { - Providing a support package } \\
2 \text { - } 10 \text { weekly sessions by phone } \\
\text { for } 30 \text { minutes and in person for } \\
\text { each session for } 25 \text { minutes } \\
3 \text { - Before, after the intervention, } 2 \text {, } \\
4 \text { and } 6 \text { months after the start of } \\
\text { the intervention }\end{array}$ & $\begin{array}{l}\text { Providing a support package in both } \\
\text { cases has led to the management of } \\
\text { distress in patients and their } \\
\text { caregivers. In this study, the results } \\
\text { were expressed separately for each } \\
\text { subgroup. It should be noted that all } \\
\text { items reported at different times were } \\
P<0.05 \text {. }\end{array}$ \\
\hline 2 & $\begin{array}{l}\text { Gabriel et al. } \\
\quad 2018\end{array}$ & South Africa & $\begin{array}{l}\text { Evaluation of the } \\
\text { effectiveness of the } \\
\text { psychosocial intervention } \\
\text { on quality of life and care } \\
\text { burden }\end{array}$ & $18-60$ & $\begin{array}{l}108 \\
\text { IG: } 54 \\
\text { CG: } 54\end{array}$ & $\begin{array}{l}\text { CQOLC } \\
\text { ZBI }\end{array}$ & $\begin{array}{l}\text { 1. Psychosocial intervention } \\
2 \text { - } 6 \text { weekly sessions for } 90 \\
\text { minutes } \\
\text { - Before and the sixth week and } \\
\text { the twelfth week }\end{array}$ & $\begin{array}{l}\text { The psychosocial intervention } \\
\text { improved the quality of life and } \\
\text { reduced the care burden in breast } \\
\text { cancer patients' caregivers. } \\
\mathrm{P}=0 / 020 \text { quality of life } \\
\mathrm{P}=0 / 018 \text { times care }\end{array}$ \\
\hline 3 & $\begin{array}{l}\text { Gabriel et al. } \\
\quad 2018\end{array}$ & Portugal & $\begin{array}{l}\text { The effect of motivational } \\
\text { interviewing on improving } \\
\text { social support for breast } \\
\text { cancer patients undergoing } \\
\text { chemotherapy and their } \\
\text { caregivers }\end{array}$ & $25-74$ & $\begin{array}{l}32 \\
\text { Caregiver: } 18 \\
\text { Patient :18 }\end{array}$ & SSS & $\begin{array}{l}1 \text { - Motivational interview } \\
2 \text { - } 4 \text { sessions of } 30 \text { minutes } \\
\text { 3. Before and immediately after } \\
\text { the intervention }\end{array}$ & $\begin{array}{l}\text { The results of the study showed that } \\
\text { motivational interviewing could } \\
\text { increase social support in patients and } \\
\text { their caregivers. } P<0.001\end{array}$ \\
\hline 4 & $\begin{array}{l}\text { Kucheknejad } \\
\text { et al. } 2016\end{array}$ & Iran & $\begin{array}{l}\text { The effect of education on } \\
\text { the care burden of } \\
\text { caregivers of breast cancer } \\
\text { patients }\end{array}$ & $18-60$ & $\begin{array}{l}60 \text { Caregiver } \\
\text { IG: } 30 \\
\text { CG: } 30\end{array}$ & $\begin{array}{l}\text { Caregiver strain } \\
\text { index question }\end{array}$ & $\begin{array}{c}1 \text { - Education } \\
2 \text { - } 2 \text { face to face sessions and } 4 \\
\text { telephone sessions for } 30 \text { to } 40 \\
\text { minutes } \\
3 \text { - Before and } 6 \text { weeks later }\end{array}$ & $\begin{array}{l}\text { Training significantly reduces the } \\
\text { burden of care on caregivers. } \\
\qquad \mathrm{P}=0 / 01\end{array}$ \\
\hline 5 & $\begin{array}{l}\text { Bahrami et } \\
\text { al. } \\
2013\end{array}$ & Iran & $\begin{array}{l}\text { The effect of COPE support } \\
\text { package on the case load } \\
\text { and quality of life of } \\
\text { caregivers of breast cancer } \\
\text { patients }\end{array}$ & $18-60$ & $\begin{array}{l}64 \text { Caregiver } \\
\text { IG: } 32 \\
\text { CG: } 32\end{array}$ & $\begin{array}{l}\text { Caregiver caring } \\
\text { burden } \\
\text { questionnaire } \\
\text { CQOLC } \\
\text { WHOQOL - BREF }\end{array}$ & $\begin{array}{l}\text { 1. COPE support package } \\
2 \text { - } 4 \text { sessions of } 45 \text { to } 60 \text { minutes } \\
3 \text { - Before and after the } \\
\text { intervention }\end{array}$ & $\begin{array}{l}\text { The study results showed that the care } \\
\text { burden and quality of life of caregivers } \\
\text { of breast cancer patients are reduced } \\
\text { and improved. } \\
\mathrm{P}<0.01\end{array}$ \\
\hline 6 & $\begin{array}{l}\text { Northouse } \\
\text { et al. } \\
2005\end{array}$ & U.S. & $\begin{array}{c}\text { The effect of family-centred } \\
\text { education on the quality of } \\
\text { life of caregivers of breast } \\
\text { cancer patients }\end{array}$ & $21-86$ & $\begin{array}{c}134 \\
\text { IG: } 69 \\
\text { CG: } 65\end{array}$ & $\begin{array}{c}\text { Appraisal of } \\
\text { caregiving scale } \\
\text { Appraisal of illness } \\
\text { scale } \\
\text { Karnofsky } \\
\text { performance } \\
\text { status scale } \\
\text { Beck hopelessness } \\
\text { scale } \\
\text { OSQ } \\
\text { FACT - G } \\
\text { SF - } 36 \\
\end{array}$ & $\begin{array}{c}1 \text { - Education } \\
2 \text { - } 5 \text { face to face and telephone } \\
\text { sessions } \\
\begin{array}{c}3 \text { - Before, } 3 \text { months and then } 6 \\
\text { months later }\end{array}\end{array}$ & $\begin{array}{c}\text { Family based education in a short time } \\
\text { improved the quality of life of patients. } \\
\text { All items in the first follow-up were } \mathrm{P} \\
<0.05 \\
\text { Nevertheless, in the six month follow- } \\
\text { up, the announced results were not } \\
\text { significant. } \\
\mathrm{P}>0.05\end{array}$ \\
\hline \multicolumn{9}{|c|}{ Table 2. Description of Studies } \\
\hline
\end{tabular}




\section{Findings - Search Results and Description of Studies}

Initially, 28,188 articles were obtained using search strategies. Also, 8 articles were found in a manual search. In the next step, duplicate and unrelated studies were eliminated, and 113 studies remained. Then 94 studies were reviewed after reviewing the abstracts, and 13 other studies were deleted after studying the full text of the articles, and finally, 6 studies were selected (Figure 1).

\section{Literature Review - Participants}

Participants in all studies were caregivers of patients with breast cancer. In 3 studies, in addition to caregivers, patients were also present. $32,44,45$ Participants in five studies were mixed $32,44-47$ and in only one study, women participated. ${ }^{48}$ The age of the participants ranged from 18 to 86 years. All studies shared inclusion criteria.

\section{Description of Interventions \\ Training}

Training is any pre-designed activity or strategy that aims to create learning in learners. This treatment program's primary purpose is to learn more about the disease and increase an individual's awareness in areas related to their conditions. ${ }^{48}$ Terry et al. conducted training sessions for caregivers and their patients by comparing the two counseling and training interventions. In every 10-to-25-minute sessions for caregivers and cancer patients, they described issues such as familiarity with cancer, treatment steps, a healthy lifestyle, and the importance of nutrition and exercise. ${ }^{32}$ In another study conducted by Kuchaknejad et al. caregivers of patients with cancer were trained. In this study, treatment sessions were conducted in person and by telephone. In 4 face to face and 2 telephone sessions for 30 to 40 minutes each, the researcher explained issues such as providing information about cancer, nutrition and adequate sleep and rest, managing the side effects of chemotherapy, identifying concerns and information needs of caregivers, and addressing them. Finally, caregivers were provided with a booklet containing the meeting summary to consolidate the caregivers' information. ${ }^{48}$

\section{Support Package}

The purpose of the support program in the interventions is to provide programs according to caregivers' needs, such as providing information about the disease and medical services. These programs are available for patients and their caregivers in order to meet their needs. ${ }^{45}$ Northouse et al. developed a support package based on five essential needs of caregivers and patients' families. These five parts of the caregivers' need were held in five sessions (without announcing the sessions' time). Recognizing the needs of family members, encouraging participation in solving each other's problems, encouraging optimism, strengthening family members' coping strategies, and providing information on cancer and its treatments were among the topics discussed at the meetings. 45 In another study, Bahrami et al. Provided a COPE based support package in four sessions of 45 to 60 minutes to strengthen optimism, creativity, planning, and providing specialized information to meet caregivers' needs. ${ }^{47}$

\section{MOTIVATIONAL INTERVIEW}

Motivational interviewing is one of the cognitive - behavioural therapy techniques. Applying this technique alone or other cognitive - behavioural therapy techniques can help reduce the symptoms of psychological disorders. The motivational interviewing technique is mostly used to help patients who are willing to make meaningful behavioural changes. ${ }^{49}$ Carla et al. conducted research in which they used motivational interviewing techniques to build and strengthen social support in cancer patients' caregivers. They performed all prethought, thought, preparation, activity, and maintenance stages in 4 sessions of 30 minutes each. During the sessions, the therapist defined social support, examining participants' perceptions of the issue and, if necessary, he/she tried to correct their perception. The therapist also encouraged patients to use the support resources, provided information about the illness, talked about the illness, and invited them to give feedback on their feelings towards cancer. Besides, the therapist helped to create a sense of social cohesion in the patient, improved mood, and encouraged leisure entertainment.

\section{PSYCHOSOCIAL INTERVENTION}

Psychosocial interventions are a set of processes to improve their social activities or create mental health in patients. This intervention is performed by a group of psychologists, social workers, and doctors and increases the individual's ability to adapt to psychological and social pressures. In addition to reducing mental distress such as stress and the burden of care on caregivers, these interventions improve their daily activities. $^{32}$ Gbril et al. performed psychosocial intervention in the form of a clinical trial. They tried to provide essential information about breast cancer, define the role of caregiver and its importance, strengthen communication strategies to prevent misunderstanding, and improve communication skills. They also attempted to improve the interaction between caregiver and patient address. They discussed the emotional aspects of caring, managing, dealing with patient feelings and self-care and the importance and strategies for promoting it during 6 weekly sessions of 90 minutes each.

\section{Tool}

The measured outcome has been different depending on the type of study. Two studies examined the burden of care in caregivers of patients with breast cancer. Both studies used the CQOLC (Caregiver Quality of Life Index - Cancer) questionnaire. In addition to the mentioned tools, one study employed WHOQOL - BREF (World Health Organization Quality of Life) to assess the quality of life, and another one used the SF - 36 questionnaire to measure the same criteria. In 4 other studies, the care burden and status of caregivers and patients were measured using questionnaires, appraisal of caregiving scale, appraisal of disease scale, Karnofsky performance status scale, ZBI (Zarit Burden Interview), caregiver strain index questionnaire, GSDS (General Symptom Distress Scale), PROMIS (Patient Reported Outcome Measurement Information System). 
SSS (Social Support Scale) was also used in a study to assess social support in caregivers and patients with breast cancer. In addition to examining the quality of life of caregivers, a study also examined the level of hope among caregivers and patients.
This study used the Beck hopelessness scale for caregivers and cancer patients. One study applied the functional assessment of cancer therapy: General (FACT - G) questionnaire to assess patients 'and caregivers' perceptions of therapeutic performance.

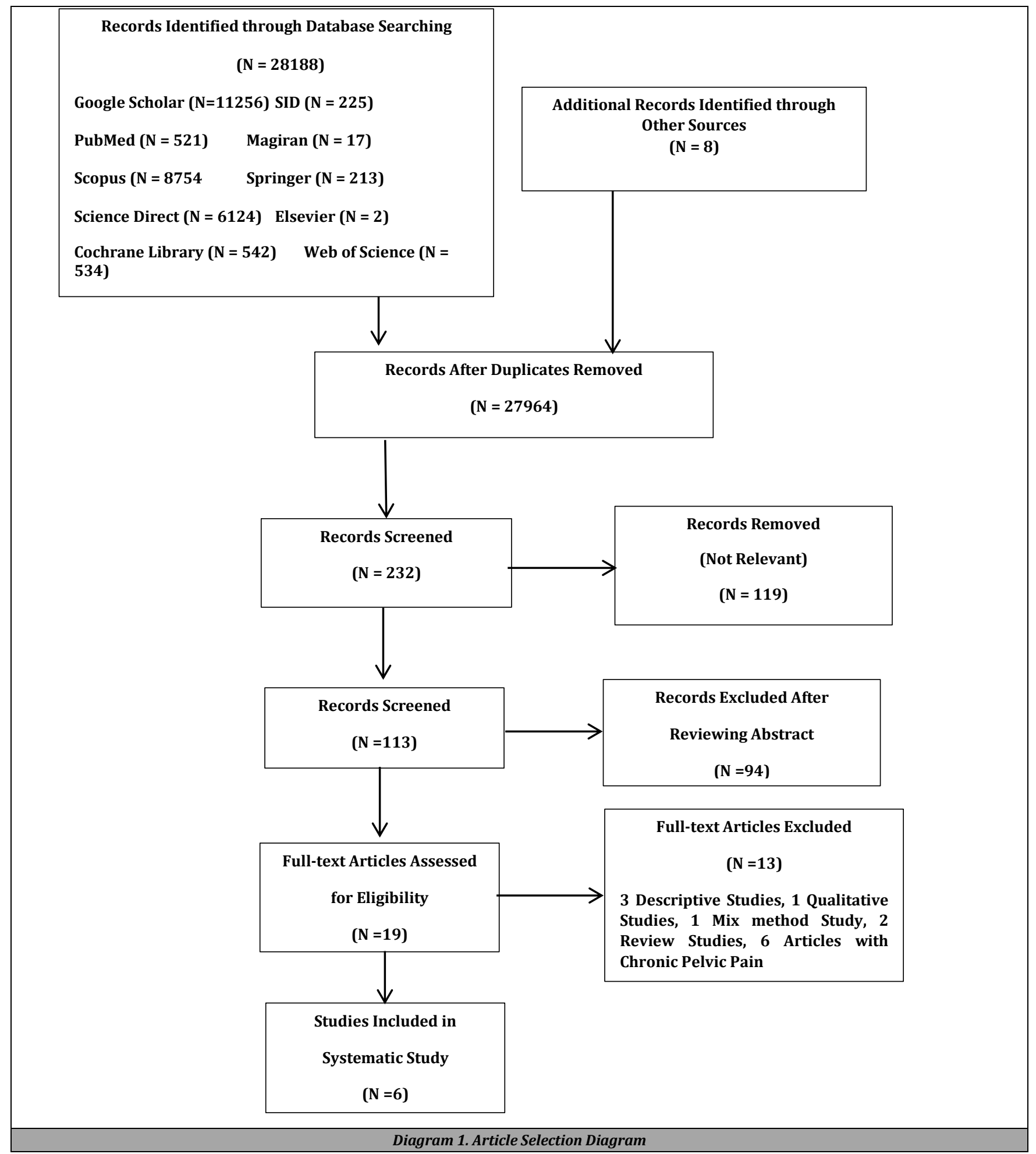

\section{DISCUSSION}

In this systematic review, 6 interventional studies were examined to evaluate the impact of effective psychological and non-psychological interventions on promoting mental health in breast cancer patients. Health care providers can use this study to develop and implement effective psychological and non-psychological interventions in promoting the mental health of caregivers of patients with breast cancer and improve their quality of life. In the meantime, 3 other studies have intervened on both caregivers and also the patients. In a 
study conducted by Terry et al. (2019), caregivers and cancer patients were both intervened and evaluated in the southwestern United States. This study helped strengthen social support and reduce distress symptoms by providing a support package for patients and their caregivers. In the same study, participants were evaluated immediately after the intervention, then 4 and 6 months after the intervention. It was found that the positive effects of treatment sessions were practical and lasting. ${ }^{32}$ Bahrami et al. (2013) obtained a similar result suggesting a support package (with different content from the previous study).

They described the sessions as useful and effective for caregivers by presenting four sessions of 45 to 60 minutes each and reviewing meetings before and after them. ${ }^{47}$

In 2005, Northouse et al. helped patients and their caregivers improve the quality of life by educating cancer patients and their family caregivers in five sessions. They followed the results of the intervention sessions for 3 and 6 months. The 3 month follow-up results were statistically significant, and the findings of 6 month follow-up were qualitatively significant but not statistically significant. The sessions were unstable as considering the stages of breast cancer were not included in the inclusion criteria, during which there was a possibility of metastasis, exacerbation, or change of stages. The mismatch of important and influential factors in the inclusion criteria is a crucial factor that was not considered in this study. 45 Kuchaknejad et al. 2016, examined the effect of education on caregivers of patients with breast cancer in Iran. They found that education is effective in reducing the burden of care in caregivers. The survey was conducted through 6 telephone and in person interview sessions that lasted 30 to 40 minutes. Follow-up was performed the 6 weeks after intervention and the results were found to be effective and stable. Thus, it can be concluded that using the principles of a clinical trial, non-psychological interventions, promoting social awareness, improving quality of life, increasing hope, reducing the burden of care, improving symptoms of distress in caregivers and their patients. ${ }^{48}$

Carla and colleagues (2017) increased social support for caregivers and patients in Portugal using motivational interviewing techniques in intervention sessions. They strengthened social support in patients and their caregivers by performing psychological intervention in 4 sessions of 30 minutes each.

This study was quasi - experimental without a control group in which they examined the participants before and after the study. One of the positive points in this study that distinguished it from other similar studies was separate intervention sessions for patients and caregivers. The results of this compelling study in the field of social protection were announced.

Gabril et al. (2018) performed a psychosocial intervention to permanently improve the quality of life of caregivers of patients with cancer. They also examined the care load variable in caregivers. The results were effective after 6 sessions of 90 minutes each. Evaluations were performed before and immediately after the intervention as well as 12 weeks after the start of the intervention. In all these times, the results of the study were statistically significant and effective.
In general, a review of studies indicates that psychological interventions (motivational interviews, psychological and social interventions) and non-psychological interventions (education and support package) can be used as effective interventions in the mental health of caregivers of patients with cancer. In all the studied papers, the interventions were performed by specialized people such as psychiatrists, psychologists, trained helpers, and trained instructors. Also, long term follow-ups in most studies (3 months, 6 months, 6 weeks, and 12 weeks), as well as the relative stability of results in follow-ups (except for one study), can be considered as one of the main reasons why such interventions are found to be effective in improving the mental health of caregivers of patients with breast cancer. However, some critical factors were not considered in these studies. For example, in the study carried out by Carla (2017) and Terry (2019), the study's generalizability and validity are considerably low as there was no control group. Also, in research performed by Carla and Bahrami, the intervention's effect was evaluated only before and after the intervention, and the lack of follow-up was a significant disadvantage.

Northouse et al. (2005) also carried out their study without considering the inclusion criteria and complete assimilation of participants. Not all interventions took into account the relationship between caregivers and the degree of intimacy with the patient. Failure to consider the gender and relationship of caregivers with the patient leads to overlooking their needs. Observing the caregiver - patient relationship in collecting research samples makes the content of the sessions specialized for the participants. Holding therapy meetings in some studies in patients' presence held back caregivers from expressing their authentic feelings.

\section{CONCLUSIONS}

The present study results show that all psychological and nonpsychological interventions mentioned in the studies are useful in promoting knowledge and mental health in caregivers of patients with breast cancer in the short term. However, since the number of studies in this field was limited, and only 2 studies were of good quality, it seems that to access more substantial evidence to implement effective interventions in promoting mental health, more and better research is needed.

\section{Limitations}

One of the limitations of this study was the lack of access to some studies full text, and we also excluded studies other than English and Persian publications.

Financial or other competing interests: All authors received grants from Mazandaran University of Medical Sciences. This project has been done with the financial support of Mazandaran University of Medical Sciences (project code: 8850). The researchers thank the Student Research Committee of Mazandaran University of Medical Sciences for supporting this project.

Disclosure forms provided by the authors are available with the full text of this article at jemds.com. 


\section{REFERENCES}

[1] Glajchen M. The emerging role and needs of family caregivers in cancer care. J Support Oncol 2004;2(2):14555.

[2] Hashemian M, Fallahi A, Hosseini VM, et al. Evaluation of the quality of life of female family caregivers of patients with breast cancer in Iran (2013). Journal of Midwifery and Reproductive Health 2017;5(1):821-7.

[3] Jazayeri SB, Saadat S, Ramezani R, et al. Incidence of primary breast cancer in Iran: ten-year national cancer registry data report. Cancer Epidemiol 2015;39(4):51927.

[4] Jemal A, Bray F, Center MM, et al. Global cancer statistics. CA Cancer J Clin 2011;61(2):69-90.

[5] Moosavi S, Rohani C. Critical appraisal of the randomized controlled trial studies reports in nursing journals. Iranian Journal of Nursing Research 2016;11(3):37-47.

[6] Vostakolaei FA, Broeders MJ, Mousavi SM, et al. The effect of demographic and lifestyle changes on the burden of breast cancer in Iranian women: a projection to 2030 . Breast 2013;22(3):277-81.

[7] Wells-Di Gregorio S, Carpenter KM, Dorfman CS, et al. Impact of breast cancer recurrence and cancer-specific stress on spouse health and immune function. Brain Behav Immun 2012;26(2):228-33.

[8] Lutgendorf SK, Laudenslager ML. Care of the caregiver: stress and dysregulation of inflammatory control in cancer caregivers. J Clin Oncol 2009;27(18):2894-5.

[9] Hasson-Ohayon I, Goldzweig G, Braun M, et al. Women with advanced breast cancer and their spouses: diversity of support and psychological distress. Psychooncology 2010;19(11):1195-204.

[10] Steiner JL, Wagner CD, Bigatti SM, et al. Depressive rumination and cognitive processes associated with depression in breast cancer patients and their spouses. Fam Syst Health 2014;32(4):378-88.

[11] Mancini J, Baumstarck-Barrau K, Simeoni MC, et al. Quality of life in a heterogeneous sample of caregivers of cancer patients: an in-depth interview study. Eur J Cancer Care 2011;20(4):483-92.

[12] Hoga LAK, Mello DS, Dias AF. Psychosocial perspectives of the partners of breast cancer patients treated with a mastectomy: an analysis of personal narratives. Cancer Nurs 2008;31(4):318-25.

[13] Cochrane BB, Lewis FM. Partner's adjustment to breast cancer: a critical analysis of intervention studies. Health Psychol 2005;24(3):327-32.

[14] Woloski-Wruble A, Kadmon I. Breast cancer: reactions of Israeli men to their wives' diagnosis. European Journal of Oncology Nursing 2002;6(2):93-9.

[15] Bakhshi RMY, Reza T, Dehghannejad N, et al. Evaluation of the challenges and needs of leukemia patients in the diagnosis and treatment of leukemia in iran from the experts point of view. Journal of Zanjan University of Medical Sciences 2014;(91)22:61-72.

[16] Rezaei H, Fathi M, Roshani D, et al. Correlation between spiritual well-being and family caregiver burden in patients with cancer. Iranian Journal of Rehabilitation Research 2019;6(2):115-24.

[17] Safaeian Z, Hejazi SS, Delavar E, et al. The relationship between caregiver burden and depression, anxiety and stress in family caregivers of cancer patients referred to Imam Reza Hospital in Bojnurd City. Iranian Journal of Psychiatric Nursing 2017;5(3):7-14.

[18] Geng HM, Chuang DM, Yang F, et al. Prevalence and determinants of depression in caregivers of cancer patients: a systematic review and meta-analysis. Medicine (Balimore) 2018;97(39):e11863.

[19] Sajjadian A, Heidari L, Mokhtarihesari P. Caring problems in domestic caregivers affected to breast cancer. Iran Breast Dis J 2015;8(2):7-14.

[20] Taleghani F, Yekta ZP, Nasrabadi AN. Coping with breast cancer in newly diagnosed Iranian women. J Adv Nurs 2006;54(3):265-72.

[21] Hoellen F, Wagner JF, Lüdders DW, et al. Anxiety in caregiving partners of breast cancer patients. Arch Gynecol Obstet 2019;300(4):993-1005.

[22] Nasiri A, Taleghani F, Irajpour A. Men's sexual issues after breast cancer in their wives: a qualitative study. Cancer Nurs 2012;35(3):236-44.

[23] Mohammad NH, Walter AW, Van Oijen MGH, et al. Burden of spousal caregivers of stage II and III esophageal cancer survivors 3 years after treatment with curative intent. Suppor Care in Cancer 2015;23(12):3589-98.

[24] Awadalla AW, Ohaeri JU, Gholoum A, et al. Factors associated with quality of life of outpatients with breast cancer and gynecologic cancers and their family caregivers: a controlled study. BMC Cancer 2007;7(1):102.

[25] Mantani T, Saeki T, Inoue S, et al. Factors related to anxiety and depression in women with breast cancer and their husbands: role of alexithymia and family functioning. Support Care Cancer 2007;15(7):859-68.

[26] Steptoe A, Hamer M, Chida Y. The effects of acute psychological stress on circulating inflammatory factors in humans: a review and meta-analysis. Brain Behav Immun 2007;21(7):901-12.

[27] Li Q, Mak YW, Loke AY. Spouses experience of caregiving for cancer patients: a literature review. Int Nurs Rev 2013;60(2):178-87.

[28] Morgan MA, Small BJ, Donovan KA, et al. Cancer patients with pain: the spouse/partner relationship and quality of life. Cancer Nurs 2011;34(1):13-23.

[29] Rezaei Z, Sani MS, Ostadhashemi L, et al. Surveying the quality of life of mothers with children with cancer in Iran. Koomesh 2018;20(3):425-31.

[30] Goedendorp MM, Gielissen MFM, Verhagen CAHHVM, et al. Development of fatigue in cancer survivors: a prospective follow-up study from diagnosis into the year after treatment. J Pain Symptom Manage 2013;45(2):21322.

[31] Solehati T, Napisah $P$, Rahmawati $A$, et al. Penatalaksanaan keperawatan pada pasien kanker payudara; sistematik review. Jurnal Ilmiah Permas: Jurnal Ilmiah Stikes Kendal 2020;10(1):71-82.

[32] Badger TA, Segrin C, Sikorskii A, et al. Randomized controlled trial of supportive care interventions to manage psychological distress and symptoms in Latinas with breast cancer and their informal caregivers. Psychol Health 2020;35(1):87-106.

[33] Chow PI, Showalter SL, Gerber MS, et al. Use of mental health apps by breast cancer patients and their caregivers in the United States: protocol for a pilot pre-post study. JMIR Res Protoc 2019;8(1):e11452. 
[34] Duggleby W, Ghosh S, Struthers-Montford K, et al. Feasibility study of an online intervention to support male spouses of women with breast cancer. Oncol Nurs Forum 2017;44(6):765-75.

[35] Northouse L, Schafenacker A, Barr KLC, et al. A tailored web-based psycho-educational intervention for cancer patients and their family caregivers. Cancer Nurs 2014;37(5):321-30.

[36] Hudson PL, Aranda S, Hayman-White K. A psychoeducational intervention for family caregivers of patients receiving palliative care: a randomized controlled trial. J Pain Symptom Manage 2005;30(4):329-41.

[37] Cipolletta S, Simonato C, Faccio E. The effectiveness of psychoeducational support groups for women with breast cancer and their caregivers: a mixed methods study. Front Psychol 2019;10:288.

[38] Moosazadeh M, Hamzehgardeshi Z, Elyasi F, et al. The effect of therapeutic-supportive interventions on body image in women with breast cancer: a systematic review. Journal of Health in the Field 2017;5(1).

[39] Jadad AR, Moore RA, Carroll D, et al. Assessing the quality of reports of randomized clinical trials: is blinding necessary? Control Clin Trials 1996;17(1):1-12.

[40] Li J, Liu Z, Chen R, et al. The quality of reports of randomized clinical trials on traditional Chinese medicine treatments: a systematic review of articles indexed in the China national knowledge infrastructure database from 2005 to 2012. BMC Complement Altern Med 2014;14(1):362.

[41] Bridoux V, Moutel G, Roman H, et al. Methodological and ethical quality of randomized controlled clinical trials in gastrointestinal surgery. J Gastrointest Surg 2012;16(9):1758-67.
[42] Emami-Sahebi A, Elyasi F, Yazdani-Charati J, et al. Psychological interventions for nausea and vomiting of pregnancy: a systematic review. Taiwan J Obstetr Gynecol 2018;57(5):644-9.

[43] Wang G, Mao B, Xiong ZY, et al. The quality of reporting of randomized controlled trials of traditional Chinese medicine: a survey of 13 randomly selected journals from mainland China. Clin Ther 2007;29(7):1456- 67.

[44] Mourão CML, Fernandes AFC, Moreira DP, et al Motivational interviewing in the social support of caregivers of patients with breast cancer in chemotherapy. Rev Esc Enferm USP 2017;51:e03268.

[45] Northouse L, Kershaw T, Mood D, et al. Effects of a family intervention on the quality of life of women with recurrent breast cancer and their family caregivers. Psychooncology 2005;14(6):478-91.

[46] Gabriel IO, Mayers PM. Effects of a psychosocial intervention on the quality of life of primary caregivers of women with breast cancer. Eur J Oncol Nurs 2019;38:8591.

[47] Bahrami M, Farzi S. The effect of a supportive educational program based on COPE model on caring burden and quality of life in family caregivers of women with breast cancer. Iran J Nurs Midwifery Res 2014;19(2):119-26.

[48] Nejad ZK, Aghdam AM, Hassankhani H, et al. The effects of a patient-caregiver education and follow-up program on the breast cancer caregiver strain index. Iran Red Crescent Med J 2016;18(3):e21627.

[49] Dennett AM, Shields N, Peiris CL, et al. Motivational interviewing added to oncology rehabilitation did not improve moderate-intensity physical activity in cancer survivors: a randomised trial. J Physiother 2018;64(4):255-63. 